\title{
Introducción
}

\section{Espacio público: sexualidad, cuerpo y Género Prácticas, representaciones y discursos}

\author{
José Octavio Hernández Sancén \\ Universidad Pablo de Olavide (Sevilla/España) \\ oct.sancen@gmail.com \\ Laura Recalde Burgueño \\ Universidad de la República (Montevideo/Uruguay) \\ laurarecalde4@gmail.com
}

El monográfico que aquí presentamos tiene como punto de partida la aventura de crear una propuesta de trabajo juntxs, cada unx desde su formación y experiencia y a partir de nuestro encuentro en la Ciudad de México 2018 durante el IV Congreso Internacional sobre Estudios de Diversidad Sexual en Iberoamérica (CIEDSI). En aquel entonces nació la inquietud de materializar la idea en un número especial en la Revista del Laboratorio Iberoamericano para el Estudio Sociohistórico de las Sexualidades (RELIES) dedicado al estudio del espacio público y la sexualidad desde diversas aristas y enfoques. Ahora podemos decir que el presente número ve la luz.

Desde nuestra concepción, los espacios públicos las representaciones, prácticas y discursos sobre la sexualidad, el cuerpo y el género cambian en función del momento histórico, el contexto social y cultural del que se trate. El cuerpo, el género y la sexualidad siempre están espacializados (McDowell, 1999) y los espacios públicos, al igual que los privados, son sitios para el control y supervisión de la sexualidad y las expresiones de género; siendo además escenarios de experiencias de goce, experimentación y resistencias.

Desde un enfoque heurístico, creemos que las formas de regulación sexo-genéricas se articulan y reproducen de manera diferente en los espacios públicos, a diferencia de los privados. Por lo tanto, pueden ser objeto de estudio y análisis desde diversas miradas multisituadas que las complejicen en sus diversas y singulares relaciones. 
La categoría de espacio público nos resulta útil no sólo para reflexionar sobre su relación con los discursos, prácticas y representaciones de las sexualidades a nivel social, sino también con la emergencia de otras aristas que, de manera adyacente, revelan el carácter productor y emancipador del cuerpo y del género con relación al espacio.

Siguiendo a Delgado (2011), el espacio público puede entenderse como espacio ideológico y productor de hegemonías sexuales y de género que significan los procesos de apropiación del mismo. Por otro lado, si pensamos en las relaciones de poder que se producen e invisibilizan en los espacios públicos con respecto a la sexualidad, el cuerpo y al género, se revelan lógicas hegemónicas que conceden al sexo heterosexual la respuesta unilateral del deseo, revelando al binomio hombre/mujer como la única expresión e identidad de género posible.

De esta forma se operativizan imaginarios socio-sexuales que no solo sexualizan los espacios, sino que producen modelos de subjetividad "ideales" y "excluyentes" que son marcados con indicadores espaciales (Sabsay, 2011). En los espacios públicos, y en las relaciones sociales que ellos contienen, se producen y reproducen dinámicas de poder en donde se establecen jerarquías entre sujetxs subalternxs y sujetxs privilegiadxs evidenciando de esta manera la densidad y complejidad de los discursos y las representaciones que se materializan en las prácticas cotidianas.

La propuesta que aquí se presenta reúne artículos que convergen y complejizan, desde distintos abordajes disciplinares y líneas de investigación, el debate entre estos tópicos, con la intensión de profundizar la reflexión en torno al estudio del espacio y su interrelación con la sexualidad, el cuerpo y el género, haciendo énfasis en el abordaje de las llamadas identidades y sexualidades disidentes, no binarias, LGBT +, queer u otrxs.

Los ejes que articulan nuestra propuesta contemplan: el espacio público como producto, productor y reproductor de desigualdades y subalternidades en torno a la sexualidad y el género; las espacialidades urbanas como espacios apropiados, de re-significación, reivindicación y resistencias a través de colectivos disidentes o queer; la generización de los espacios, sus prácticas, discursos y representaciones desde experiencias situadas de placer y goce, vulnerabilidad y garantías legales; dinámicas de poder y estrategias de resistencia de los cuerpos, entre otros tópicos.

En "Cuerpos, signos y espacios: sobre la arquitectura panóptica de la segregación urinaria”, José Andrés Díaz Hernández nos invita a reflexionar sobre las intercepciones dinámicas entre 
cuerpos, discursos y espacios, en concreto sobre las tecnologías arquitectónicas que engendran los signos de la segregación genérica y la codificación de los cuerpos en la vida cotidiana.

Albanella Luena Chávez Turello en "Nosotras nos hacemos a nosotras mismas: Análisis psicosocial del proceso de construcción de la identidad lésbica y su relación con el espacio público y la vida en sociedad", analiza las relaciones en el proceso de construcción de la identidad de mujeres lesbianas con relación al espacio público como espacio de resignificación de su identidad social y personal.

En "Hacer la calle en dictadura. Memorias trans del terrorismo de estado en Uruguay (1973-1985)”, Gonzalo Gutiérrez aborda el espacio público, específicamente la calle, y la violencia sufrida por personas trans en el ejercicio del trabajo sexual en el contexto de la última dictadura uruguaya como parte del terrorismo de Estado.

Luisina Castelli en "Hacerse presentes. Los sujetos del feminismo y la discapacidad en la acción política", propone un encuentro entre perspectivas: las de movimientos feministas y del colectivo de personas con discapacidad, vinculados al espacio público y la acción política.

En "Espacios, relaciones y significados del sexo anónimo entre varones en México. Figuraciones entre lo alternativo a lo normativizado”, Luis Arturo Sánchez Domínguez analiza el sexo anónimo en la Ciudad de México, sus representaciones y significados para entender cómo pueden coexistir, por un lado, la alternativa transgresora de las normas morales y sexuales; y por el otro, la reafirmación de ellas en un orden heteronormativo.

Marcos Sardá Vieira en "Corpos dissidentes em associação e reconhecimento", analiza la condición precaria de la representación del cuerpo disidente por su condición de género y sexualidad en las performances artísticas de la subcultura LGBTI+. Cuestiona, a través de un análisis fenomenológico de hechos y eventos públicos en Brasil y Berlín, la precaria condición de los cuerpos e identidades disidentes en las relaciones con otros sujetos, objetos y alegorías de alcance estético en la cultura material y urbana del capitalismo tardío.

En "La Puta Madre”: Discursos y tensiones sobre el trabajo sexual en Uruguay”, Isabel Cedrés Ferrero propone discutir acerca de las tensiones coexistentes en los discursos feministas, y su relación con el trabajo sexual y la comercialización del sexo realizado por mujeres cis-género. Profundiza, en particular, en los discursos existentes en la esfera pública de Uruguay. 
Laura Recalde Burgueño en "Politizaciones fronterizas: el "lugar" de las identidades sexuales disidentes en los espacios de la ciudad" analiza cómo son politizadas las identidades disidentes en espacios de la ciudad, específicamente en el departamento de Rivera, Uruguay. Explora cómo en los espacios públicos se reproducen imaginarios sociosexuales excluyentes y desiguales que repercuten en el goce de los derechos de quienes los habitan.

Finalmente, en “"El último vagón”: sexualidad, cuerpo y espacio. Una aproximación a las prácticas homoeróticas entre hombres en el metro de la Ciudad de México”, José Octavio Hernández Sancén situado en el contexto de la megalópolis, visibiliza el complejo proceso de apropiación del espacio público del metro y propone comprender, a partir del cuerpo y la sexualidad, la construcción de los pactos de complicidad entre los usuarios-hombres en el interior del "último vagón".

Para cerrar este número nos acompaña la reseña del libro: "Que otros sean lo normal" de Leandro Colling publicado originalmente en portugués en Brasil, pero editado actualmente en español por Egales, España.

Este número tiene la intención de abrir un espacio para el intercambio de los saberes intrínsecos en las sociedades en Iberoamérica, haciendo énfasis en la producción de conocimientos de estudios emergentes que analizan la urbanidad, el territorio, la geografía, los feminismos y los colectivos con relación al cuerpo, la sexualidad y el género. Aquí dejamos para ustedes el primer monográfico de la Revista del Laboratorio Iberoamericano para el Estudio Sociohistórico de las Sexualidades (RELIES) esperando refleje el agrado que fue para nosotrxs el llevarlo adelante. 